\title{
Expression of cytokines in chicken peripheral mononuclear blood cells (PMBCs) exposed to probiotic strains and Salmonella Enteritidis
}

\author{
Eva Husáková1, Viera Spišáková1, Róbert Herich ${ }^{1}$, Martina Kolesárová1, \\ Dominika Stašová ${ }^{1}$, Mária Levkutová ${ }^{1}$, Mikuláš Levkut ${ }^{1,2}$ \\ ${ }^{1}$ University of Veterinary Medicine and Pharmacy, Košice, Slovak Republic \\ ${ }^{2}$ Neuroimmunological Institute SAS, Bratislava, Slovak Republic
}

Received May 20, 2014

Accepted October 22, 2014

\begin{abstract}
The mRNA expression of interleukin (IL)-1 $\beta$, LITAF, iNOS, macrophage inflammatory protein (MIP1-ß), and K60 were examined in peripheral blood mononuclear cells (PMBCs). The PMBCs were isolated from the chicken blood and in vitro exposed to the probiotic strains E. faecium AL41, E. faecium $\mathrm{H} 31$, L. fermentum $\mathrm{AD} 1$, and infected with Salmonella enterica serovar Enteritidis (SE147). The PMBCs were evaluated for mRNA expression levels at $24 \mathrm{~h}$ and $48 \mathrm{~h}$ post infection (p.i.) using the reverse transcriptase polymerase chain reaction (RT-PCR). The level of expression of IL- $1 ß$ and MIP $1-\beta$ was upregulated $(P<0.001)$ in the EFAL41+SE $(S$. Enteritidis + E. faecium AL41) group $48 \mathrm{~h}$ p.i. compared to $24 \mathrm{~h}$ p.i. Similarly, expression of LITAF was upregulated $(P<0.001)$ in the EFAL41 + SE group compared to the control $(\mathrm{C}$ - no infected $)$ and $S$. Enteritidis (SE) group $48 \mathrm{~h}$ p.i. In PMBCs treated with $E$. faecium $\mathrm{H} 31$ and $S$. Enteritidis expression of IL$1 ß(P<0.01)$ and chemokines K60 and MIP1- $\beta$ was upregulated $(P<0.001)$ in the EFH31 + SE group $24 \mathrm{~h}$ p.i. The iNOS showed upregulated expression $(P<0.001)$ in the EFAL41 + SE group compared to the control $24 \mathrm{~h}$ p.i. and to the $\mathrm{C}$ and SE groups $48 \mathrm{~h}$ p.i. The results showed that E. faecium AL41 demonstrated the highest immunostimulatory effect on expression of selected cytokines by chicken PMBCs after Salmonella infection. It is supposed that the differences in cytokine induction within SE groups are related to lymphocytes isolated from different animals.
\end{abstract}

$m R N A, R T-P C R$, immune system, Enterococcus faecium, in vitro

Over the course of evolution, lactic acid bacteria (LAB) have been abundant colonisers of the small intestinal mucosa, coexisting in relationships with the host. Some members of these groups exert additional probiotic properties that provide health benefits to the host via the regulation of the immune system and other physiological functions (MacDonald and Monteleone 2005; Konstantinov et al. 2008). The introduction of probiotic strains has been found to influence the established microbiota and have also been reported to exert immunomodulatory effects both in vivo and in vitro conditions. The strains of Lactobacillus, Enterococcus and others are included among the numerous microorganisms, which have been reported to show beneficial properties involving both the antibacterial effects on possible pathogenic strains and the immunomodulatory effects correlating with reductions in infections as well as improved recovery (Heineman et al. 2012; Hemarajata and Versalovic 2013). The use of probiotics is considered to be a potentially important strategy for modulating infectious and inflammatory responses in the gastrointestinal tract of the host. The effect of these probiotics is diverse and includes the modulation of the gut immune system through the interaction with gut epithelial cells and immune cells (Pamer et al. 2007). The testing of probiotics is performed by studies on cell and animal models. In vitro studies may provide valuable information, such as the mechanism through which the probiotic bacteria are effective.

Some of the important cytokines and chemokines involved in the initiation and modulation of the inflammatory immune activities in chickens include IL-1 $\beta$, LITAF, K60, MIP1- $\beta$,

Address for correspondence:

RNDr. Eva Husáková

University of Veterinary Medicine and Pharmacy

Institute of Pathological Anatomy and Pathological Physiologay

Komenského 73, 04181 Košice, Slovak Republic

Phone: +903 387151

E-mail: eva.husakova@student.uvlf.sk

http://actavet.vfu.cz/ 
and iNOS. We aimed at the determination of the levels of cytokines, particularly the proinflammatory cytokines IL- $1 \beta$ and LITAF, produced following the invasion of $S$. Enteritidis into chicken cells in vitro; and finally, to evaluate whether the strain characteristics of commensal bacteria can be immunologically effective for the prevention and treatment of Salmonella infection in chickens.

\section{Materials and Methods}

Isolation and cultivation of PMBCs from peripheral blood of poultry

Blood was collected from the vena cutanea ulnaris to $1.5 \%$ EDTA from clinically healthy poultry reared under standard conditions. Collected blood was diluted with PBS in a ratio of 1:2 and transferred to Leucoseps tube (Greiner bio-one, DE) containing histopaque-1077 (Sigma-Aldrich, UK) and centrifuged for $40 \mathrm{~min}$ at 19000 $\times g$ at $20^{\circ} \mathrm{C}$ (Hettich Rotina 420R Centrifuge, DJB Labcare, UK). Mononuclear cells were collected from the gradient interface and washed twice for $5 \mathrm{~min}$ at $16000 \times \mathrm{g}$ with PBS. Cell viability and number were determined by trypan blue exclusion. Isolated PMBCs (Peripheral Mononuclear Blood Cells) were plated in to 12-well cultivation plate (Orange Scientific, BE ) in the number of $1 \times 10^{7} \mathrm{cells} / \mathrm{ml}$, and cultured overnight $\left(39^{\circ} \mathrm{C}, 5 \%\right.$ CO2) in RPMI 1640 medium enriched with 10 mM HEPES (Lonza, BE) and 10\% FBS (Lonza, BE). After $24 \mathrm{~h}$ cultivation $200 \mu$ of $S$. Enteritidis SE147 (provided by Dr. Rychlík, VRI, Brno, Czech Republic) in the number of $1 \times 10^{8} \mathrm{CFU} / \mathrm{ml}$, and $200 \mu \mathrm{l}$ of Enterococcus faecium AL41, Enterococcus faecium $\mathrm{H} 31$ and Lactobacillus fermentum AD1 (provided by Dr. Lauková, IAP SAS, Košice, Slovakia) in a number of $1 \times 10^{9} \mathrm{CFU} / \mathrm{ml}$ were added to PMBCs in particular wells. After the addition of bacteria PMBCs were cultured for 24 and $48 \mathrm{~h}$. The cultivation of bacterial strains, culture medium and growth conditions was performed as described previously (Herich et al. 2005; Strompfová et al. 2005).

Isolation of mRNA from PMBCs

The PMBCs were harvested from each well by pipetting and centrifuged for 1 min at $8000 \times g$. Cell lysing buffer containing $\beta$-mercaptoethanol (Qiagen, USA) was added to the resulting pellet. Then, $70 \%$ ethanol was added to the whole cell lysate at the ratio of $1: 1$, and the whole mixture was homogenized using a vortex mixer (Labnet, USA) for $1 \mathrm{~min}$. This resulting cell lysate was used for isolation of RNA using the RNAeasy mini kit (Qiagen, UK) according to the manufacturer's instructions. The purity and concentration of total RNA was determined spectrophotometrically on NanoDrop 200c (Thermo Scientific, UK) and $1 \mu \mathrm{g}$ of total RNA was immediately reverse transcribed by using iScript cDNA Synthesis Kit (Bio-Rad, USA). The resulting cDNA was diluted $\times 10$ in UltraPure ${ }^{\mathrm{TM}}$ DNase/RNase-Free distilled water (Invitrogen, USA) and used as a template for qRTPCR or stored at $-20^{\circ} \mathrm{C}$ until used.

\section{RT-PCR}

The relative expression of cytokines (IL-1 $\beta$, LITAF), chemokines (K60, MIP1- $\beta$ ), and iNOS were determined. The expression levels of two house-keeping genes, glyceraldehyde-3-phosphate dehydrogenase (GAPDH), and ubiquitin (UB) were used for data normalisation. Amplification and detection of specific products were performed using the CFX 96 RT system (Bio-Rad, USA) with the following temperature-time profile: initial denaturation $15 \mathrm{~min} 95^{\circ} \mathrm{C}$ and 45 cycles: denaturation $95^{\circ} \mathrm{C}$ for $20 \mathrm{~s}$, annealing $60^{\circ} \mathrm{C}$ for $30 \mathrm{~s}$ and final elongation $72{ }^{\circ} \mathrm{C}$ for $30 \mathrm{~s}$. A melting curve from $50{ }^{\circ} \mathrm{C}$ to $95{ }^{\circ} \mathrm{C}$ with a reading at every $0.5^{\circ} \mathrm{C}$ was performed for each individual RTPCR plate. Each sample was subjected to real-time PCR in duplicate and the mean values of the duplicates were used for subsequent analysis. We also confirmed that efficiency of amplification of each target genes (including GAPDH and UB) were essentially $100 \%$ in the exponential phase of the reaction, where the quantification cycle $(\mathrm{Cq})$ is calculated. The $\mathrm{Cq}$ values of genes of interest were normalised to a mean $\mathrm{Cq}$ value of the reference genes $(\Delta \mathrm{Cq})$ and the relative expression of each representative was calculated as $2-\Delta \mathrm{Cq}$. These expression levels were then used for comparative data analysis.

\section{Statistical analysis}

Statistical analysis of obtained data was done by one-way analysis of variance (ANOVA) with post hoc Tukey multiple comparison test using GraphPad Software, statistical version 5.0 (USA). Differences between the mean values for different treatment groups were considered significant at $P<0.01 ; P<0.001$.

\section{Results}

The effect of $E$. faecium AL41 revealed upregulation $(P<0.001)$ on expression of IL-1ß in the EFAL41 + SE group compared to the control $48 \mathrm{~h}$ p.i. Similarly, in PMBCs treated with $E$. faecium $\mathrm{H} 31$ the relative expression of IL-1ß was upregulated $(P<0.01)$ in the EFH31 + SE group compared to the control and SE group 24 h p.i. (Fig. 1). 


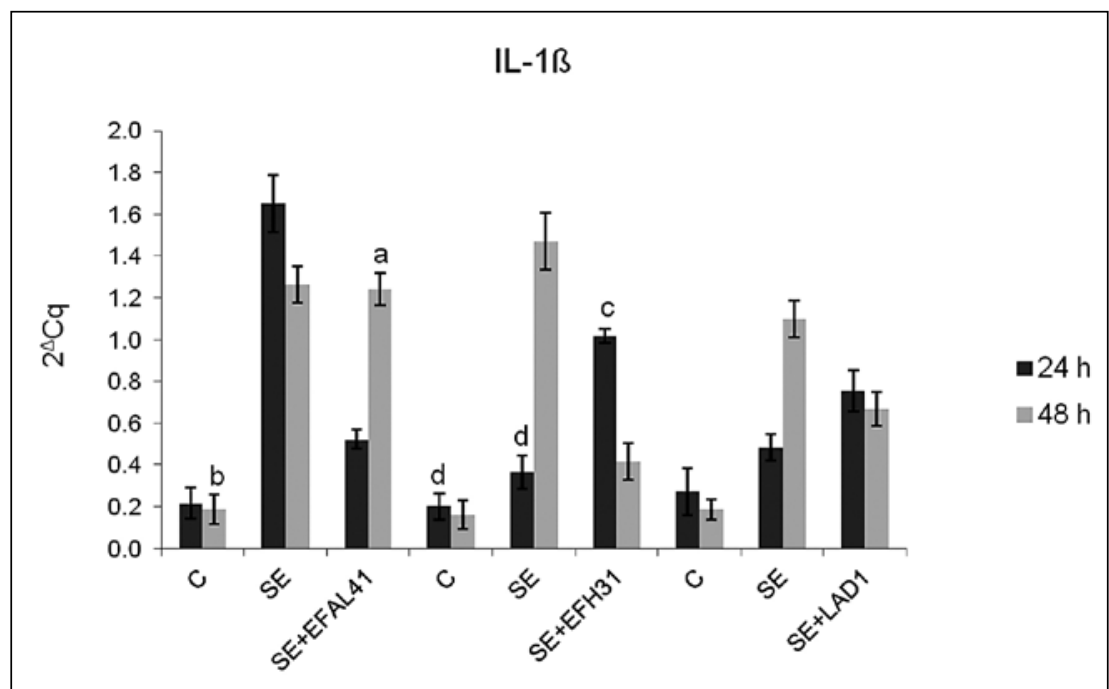

Fig. 1. Relative quantitation - mRNA of IL-1ß in PMBCs

C - control; SE - S. Enteritidis SE147, SE + EFAL41 - S. Enteritidis SE147 + E. faecium AL41; SE + EFH31 - S. Enteritidis SE147 + E. faecium H31; SE + LAD1 - S. Enteritidis SE147 + L. fermentum AD1; 24 and 48 h post infection; All values are expressed as mean \pm SD. Means with different superscripts are significantly different ${ }_{\text {ab } P}<0.001 ;$ cd $P<0.01$

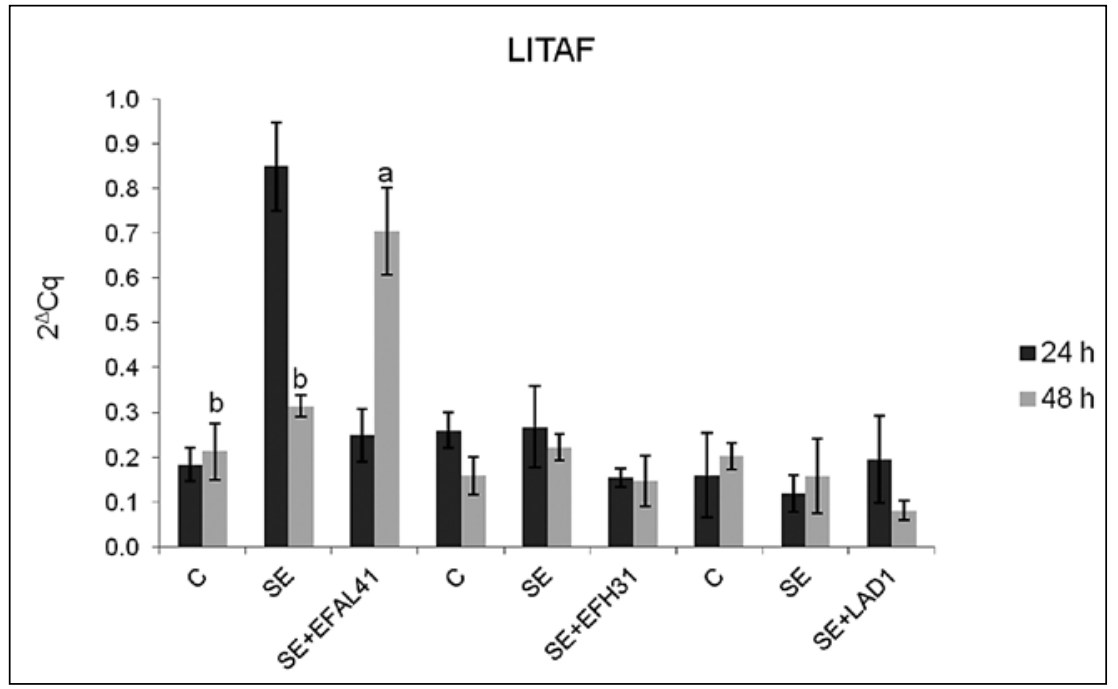

Fig. 2. Relative quantitation - mRNA of LITAF in PMBCs.

C - control; SE - S. Enteritidis SE147, SE + EFAL41 - S. Enteritidis SE147 + E. faecium AL41; SE + EFH31 - S. Enteritidis SE147 + E. faecium H31; SE + LAD1 - S. Enteritidis SE147 + L. fermentum AD1; 24 and 48 $\mathrm{h}-$ post infection; All values are expressed as mean \pm SD. Means with different superscripts are significantly different ${ }^{\text {ab }} P<0.001$ 


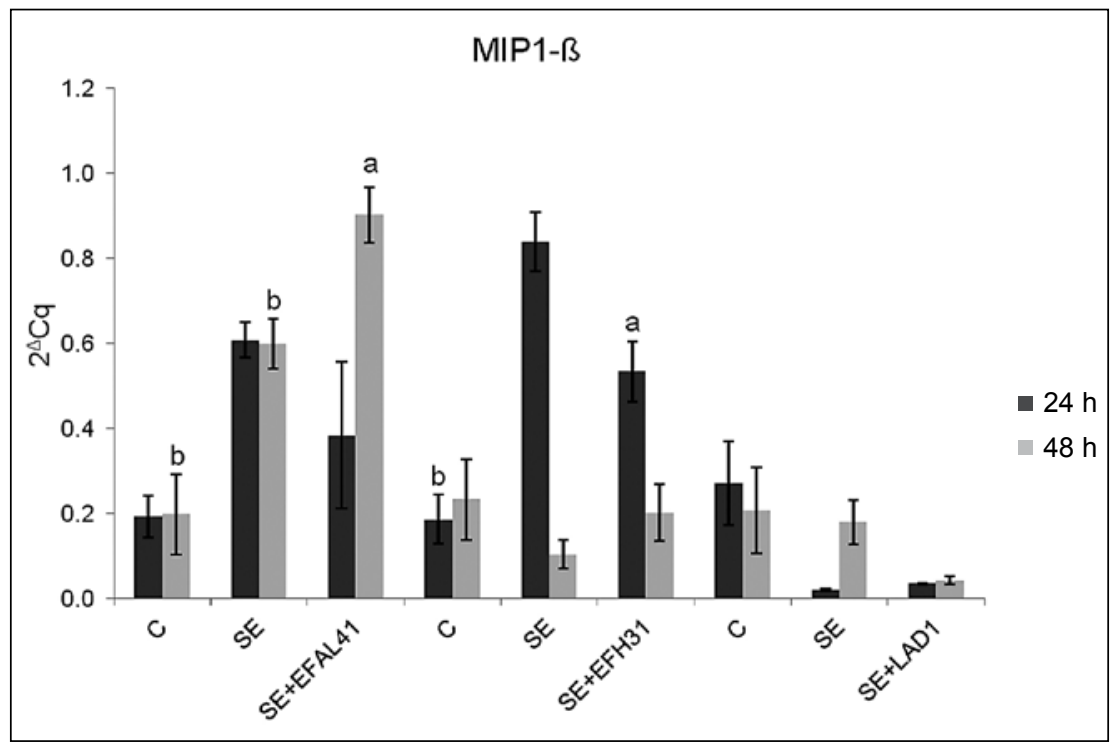

Fig. 3. Relative quantitation - mRNA of MIP1- $\beta$ in PMBCs.

C - control; SE - S. Enteritidis SE147, SE+EFAL41 - S. Enteritidis SE147 + E. faecium AL41; SE+EFH31 - S. Enteritidis SE147 + E. faecium H31; SE+LAD1 - S. Enteritidis SE147 + L. fermentum AD1; 24 and 48 h post infection; All values are expressed as mean \pm SD. Means with different superscripts are significantly different ${ }^{\text {ab }} P<0.001$

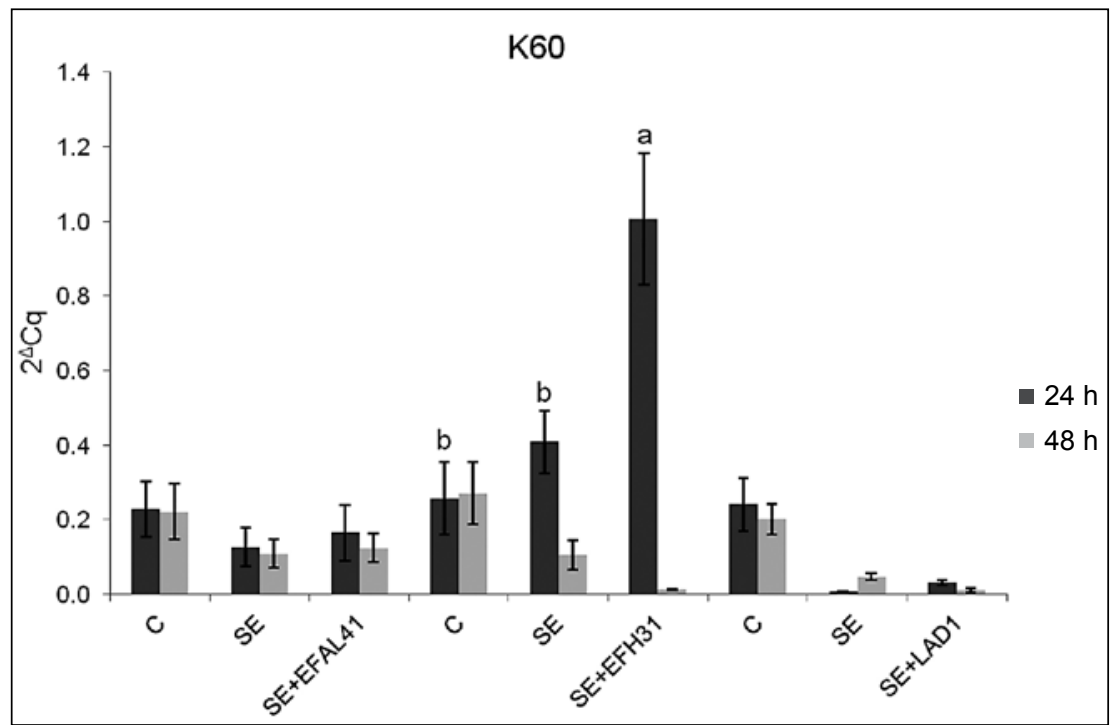

Fig. 4. Relative quantitation - mRNA of K60 in PMBCs.

C - control; SE - S. Enteritidis SE147, SE + EFAL41 - S. Enteritidis SE147 + E. faecium AL41; SE + EFH31 - S. Enteritidis SE147 + E. faecium H31; SE+LAD1 - S. Enteritidis SE147 + L. fermentum AD1; 24 and 48 h post infection; All values are expressed as mean \pm SD. Means with different superscripts are significantly different ${ }^{\mathrm{ab}} P<0.001$ 
The $24 \mathrm{~h}$ exposure of PMBCs to E. faecium AL41 did not have a stimulatory effect on relative expression of LITAF, but upregulation $(P<0.001)$ was found in the EFAL41 $+\mathrm{SE}$ group compared to the $\mathrm{C}$ and $\mathrm{SE}$ groups $48 \mathrm{~h}$ p.i. (Fig. 2).

The relative expression of chemokine MIP1- $\beta$ was upregulated $(P<0.001) 48$ h p.i., treated with E. faecium EFAL41 in the EFAL41 + SE group compared to the control. Similarly, exposure of PMBCs to E. faecium EFH31 showed upregulation $(P<0.001)$ of selected chemokines MIP1- $\beta$ and K60 in the EFH31 + SE group compared to the control (Fig. 3) and the $\mathrm{C}$ and SE groups $24 \mathrm{~h}$ p.i. (Fig. 4).

The level of expression of iNOS was upregulated $(P<0.001)$ in the EFAL41 + SE group compared to the control group $24 \mathrm{~h}$ p.i. and to the $\mathrm{C}$ and SE groups $48 \mathrm{~h}$ p.i. in response to exposure of PMBCs to probiotic strain E. faecium AL41 tested in this study (Fig. 5).

The comparison of all three tested probiotic strains in chicken PMBCs challenged with $S$. Enteritidis showed that probiotic strain E. faecium AL41 induced upregulation $(P<0.001)$ of expression of proinflammatory cytokines and chemokines compared to the probiotic strains $L$. fermentum AD1 and E. faecium $\mathrm{H} 31$.

The differences in cytokine induction within SE groups are related to lymphocytes isolated from different animals. Precisely because of different immune response of every animal, all in vitro tests included SE group, which represented particular "infectious background“".

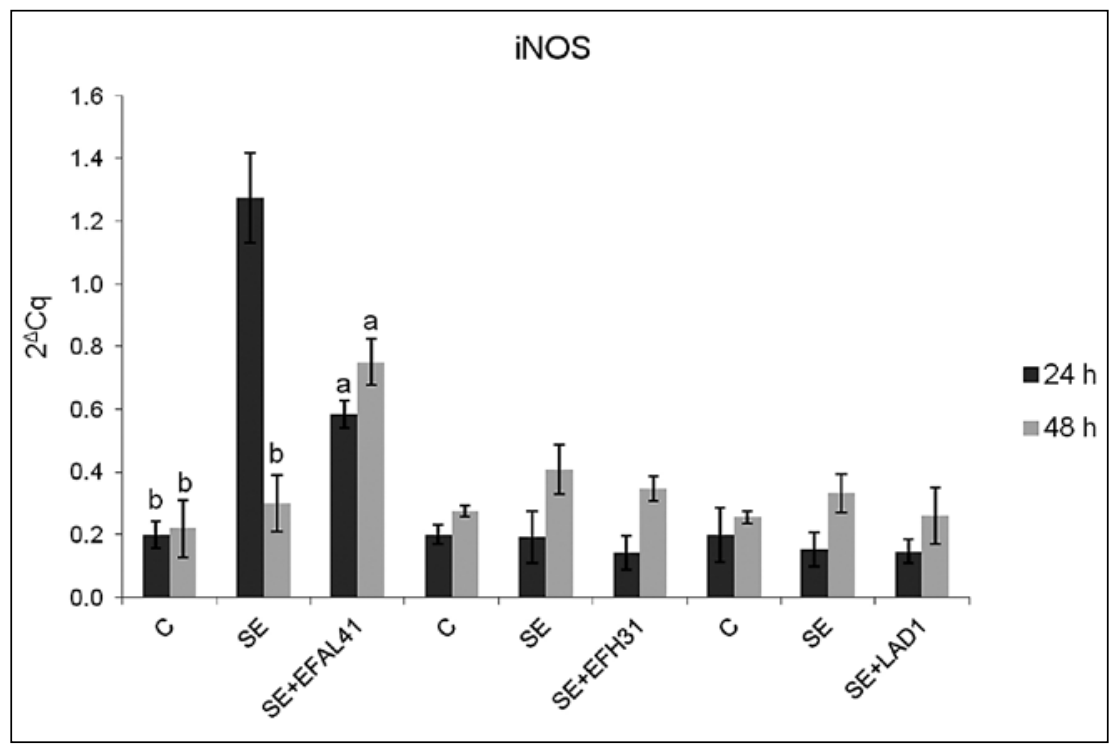

Fig. 5. Relative quantitation - mRNA of iNOS in PMBCs.

C - control; SE - S. Enteritidis SE147, SE + EFAL41 - S. Enteritidis SE147 + E. faecium AL41; SE + EFH31 - S. Enteritidis SE147 + E. faecium H31; SE+LAD1 - S. Enteritidis SE147 + L. fermentum AD1; 24 and 48 h post infection; All values are expressed as mean \pm SD. Means with different superscripts are significantly different ${ }^{\mathrm{ab}} P<0.001$

\section{Discussion}

The response of the immune system to probiotic bacteria remains controversial. Some strains modulate the cytokine production in vitro and induce a regulatory response, whereas others induce a pro-inflammatory response (Evrard et al. 2011). However, 
several studies have provided unequivocal evidence that the specific strains of probiotics are able to stimulate multiple aspects of innate immunity (Weiss et al. 2010) as well as to increase the humoral immunity (Roberfroid 2002). In the current experiment probiotic strains E. faecium AL41, E. faecium $\mathrm{H} 31$ and L. fermentum AD1 demonstrated individual response on expression of selected cytokines and chemokines in vitro. Kais er et al. (2000) described down-regulation of IL-1 $\beta$ expression after Salmonella infection leading to a reduced rapid inflammatory response in the intestine allowing the initial entry of bacteria. Similarly, our experiment demonstrated down-regulation of IL-1 $\beta$ mRNA expression 24 $\mathrm{h}$ p.i., however, $48 \mathrm{~h}$ p.i. the level of IL-1 $\beta$ mRNA was upregulated after stimulation of PMBCs with E. faecium AL41 and $S$. Enteritidis. It is interesting that regulation of IL-1 $\beta$ mRNA after application of E. faecium $\mathrm{H} 31$ and $S$. Enteritidis infected cells was upregulated $24 \mathrm{~h}$ p.i. Although little is known about the biological function of LITAF in poultry, it has been reported that the expression of this co-stimulatory molecule was upregulated in $S$. Typhimurium LPS-stimulated macrophages. It is also suggested that LITAF plays an important role in driving inflammatory responses and bacterial clearance, though its role in avian salmonellosis remains unclear and requires further investigations. Hong et al. (2006) showed that expression of LITAF to be upregulated following the in vitro stimulation of macrophages with $S$. Typhimurium LPS. The data from our experiment showed upregulation in the gene expression level of LITAF in the EFAL41 + SE group $48 \mathrm{~h}$ p.i.

The mechanisms of innate immunity are the first line of defence against pathogenic microorganisms. An integral part of this reaction is the production of nitric oxide synthase (iNOS), which has a strong bacteriostatic activity against intracellular bacteria (Richardson et al. 2009). Our results also indicate upregulation of expression of iNOS in the combined group EFAL41 + SE $48 \mathrm{~h}$ p.i., which suggests the bacteriostatic effect of E. faecium AL41. Moreover, its bacteriostatic activity demonstrated Lauková et al. (2004) after infection of gnotobiotic quails with Salmonella enterica. Meyer et al. (2007) in their in vitro study showed that some probiotic strains stimulated production of chemokines. Similar results were found by Brisbin et al. (2010) and Withanage et al. (2004) who showed that probiotic bacteria were extensively used as probiotics for the control of intestinal colonization with enteric pathogens. Chemokines are known to be produced by cells during infection or following a pro-inflammatory stimulus and prompt the migration of leukocytes to an injured, or infected site. Such inflammatory chemokines can also activate cells to raise an immune response and commence the wound healing process. K60 might be also chemoattractive for heterophils (Murphy et al. 2000). In our study the upregulation of relative expression of K60 and MIP1- $\beta$ mRNAs $24 \mathrm{~h}$ p.i. was demonstrated after treatment with E. faecium $\mathrm{H} 31$ and challenge with $S$. Enteritidis. On the other hand, upregulation of MIP1- $\beta$ mRNA was determined in the group EFAL41 + SE $48 \mathrm{~h}$ p.i.

It follows that increased expression of the studied cytokines and chemokines was demonstrated especially during combined treatments through elevated production of selected cytokines and chemokines, in response of PMBCs to application of probiotic strains E. faecium $\mathrm{H} 31$ and E. faecium AL41. Recently, in our laboratory we have determined early upregulation expression of pro-inflammatory cytokines in the caecum of chickens treated with Enterococcus faecium and challenged with $S$. Enteritidis 147 (Levkut et al. 2014). Early reaction of pro-inflammatory cytokines in chickens PMBC exposed to E. faecium AL41 was seen also in the current trial.

In conclusion, our results demonstrated that E. faecium AL41 showed the highest immunostimulatory effect from all of the tested probiotic strains on the level of relative expression of selected cytokines and chemokines after infection with $S$. Enteritidis. Furthermore, the results showed that the highest cytokine response to probiotic bacteria in our experiment was found in IL-1 $\beta$ and MIP1- $\beta$. Finally, the in vitro method used for 
selection of probiotic bacteria on the basis of cytokine activity was suitable for an in vivo trial.

\section{Acknowledgements}

This work was supported by the Grant Agency for Science of Slovak Republic VEGA-1/0313/12 and APVV0302-11.

\section{References}

Brisbin JT, Gong J, Parvizi P, Sharif S 2010: Effects of Lactobacilli on cytokine expression by chicken spleen and cecal tonsil cells. Clin Vac Immunol 17: 1337-1343

Evrard B, Coudeyras S, Dosgilbert A, Charbonnel N, Alamé J, Tridon A, Foresti Ch 2011: Dose-dependent immunomodulation of human dendritic cells by the probiotic Lactobacillus rhamnosus Lcr35. PLoS One 18: e18735

Heineman J, Bubenik S, McClave S, Martindale R 2012: Fighting fire with fire: is it time to use probiotics to manage pathogenic bacterial diseases? Curr Gastroenterol Rep 14: 343-348

Hemarajata P, Versalovic J 2013: Effects of probiotics on gut microbiota: mechanisms of intestinal immunomodulation and neuromodulation. Ther Adv Gastroenterol 6: 39-51

Herich R, Lauková A, Strompfová V, Revajová V, Levkut M, Pistl J 2005: Polymerase chain reaction detection of caecal bacteria in case of preventive application of Enterococcus faecium EK13 against Salmonella enterica subsp. Enteritidis in chickens. J Anim Feed Sci 14: 161-170

Hong YH, Lillehoj HS, Lee SH, Park DW, Lillehoj EP 2006: Molecular cloning and characterization of chicken lipopolysaccharide-induced TNF-alpha factor (LITAF). Dev Comp Immunol 30: 919-929

Kaiser P, Rothwell L, Galyov EE, Barrow PA, Burnside J, Wigley P 2000: Differential cytokine expression in avian cells in response to invasion by Salmonella Typhimurium, Salmonella Enteritidis and Salmonella Gallinarum. Microbiol 12: 3217-3226

Konstantinov SR, Smidt H, de Vos WM 2008: S layer protein A of Lactobacillus acidophilus NCFM regulates immature dendritic cell and T cell functions. Proc Natl Acad Sci 105: 19474-19479

Lauková A, Guba P, Nemcová R, Mareková M 2004: Inhibition of Salmonella enterica serovar Duesseldorf by enterocin A in gnotobiotic quails. Vet Med Czech 49: 47-51

Levkut M Jr, Revajová V, Levkutová M, Kolesárová M, Herich R, Ševčíková Z, Levkut M Sr 2014: Mucin expression and cytokines in the caecum of broilers after administration of EF55 and $S$. Enteritidis. ESVP/ ECVP Proceedings 2013. J Comp Path 150: 94

MacDonald TT, Monteleone G 2005: Immunity, inflammation, and allergy in the gut. Sci 307: 1920-1925

Meyer AL, Elmadfa I, Herbacek I, Micksche M 2007: Probiotic, as well as conventional yogurt, can enhance the stimulated production of proinflammatory cytokines. J Hum Nutr Diet 20: 590-598

Murphy PM, Baggiolini M, Charo IF, Hebert CA, Horuk R, Matsushima K, Miller LH, Oppenheim JJ, Power CA 2000: International union of pharmacology. XXII. Nomenclature for chemokine receptors. Pharmacol Rev 52: $145-76$

Pamer EG 2007: Immune responses to commensal and environmental microbes. Nat Immunol 11: 1173-1178

Richardson AR, Soliven KC, Castor ME, Barnes PD, Libby SJ, Fang FC 2009: The base excision repair system of Salmonella enterica serovar Typhimurium counteracts DNA damage by host nitric oxide. PLoS Pathog 5: 201-209

Roberfroid MB 2002: Functional foods: concepts and application to inulin and oligofructose. Br J Nutr 87: 139-144

Strompfová V, Marciňaková M, Gancarčíková S, Jonecová Z, Sciranková L, Guba P, Koščová J, Boldižárová K, Lauková A 2005: New probiotic strain Lactobacillus fermentum AD1 and its effect in Japanese quail. Vet Med Czech 50: 415-420

Weiss G, Rasmussen S, Zeuthen LH, Nielsen BN, Jarmer H, Jespersen L, Frokiaer H 2010: Lactobacillus acidophilus induces virus immune defence genes in murine dendritic cells by a toll-like receptor-2-dependent mechanism. Immunol 131: 268-281

Withanage GSK, Kaiser P, Wigley P, Powers C, Mastroeni P, Heather Brooks H, Barrow P, Smith A, Maskell D, McConnell1 I 2004: Rapid expression of chemokines and proinflammatory cytokines in newly hatched chickens infected with Salmonella enterica serovar Typhimurium. Infect Immunol 72: 2152-2159 